\title{
LXVIII. Radioactive minerals in common rocks
}

\section{J.W. Waters B.Sc.}

To cite this article: J.W. Waters B.Sc. (1909) LXVIII. Radioactive minerals in common rocks, Philosophical Magazine Series 6, 18:106, 677-679, DOI: 10.1080/14786441008636736

To link to this article: http://dx.doi.org/10.1080/14786441008636736

\section{9.}

Submit your article to this journal 준

Џ Article views: 2

Q View related articles 두 
charcoal, the tube was found to contain argon only. No lines but those due to argon could be observed in the spectrum of the gas. The volume of the argon was measured by the McLeod gauge and found to be 3 cubic mm., a quantity which could be well accounted for by contamination with air in the course of transference from one vessel to another.

As krypton is very easily absorbed by charcoal in liquid air, it was thought advisable to make sure that none had remained in the large bulb used in the first part of the investigation. This bulb was maintained at a lemperature of $220^{\circ} \mathrm{C}$. for about 6 hours by means of an electric heater, and the expelled gas collected. The gas was practically all carbon dioxide, and after absorbing most of it with hydrated potassium hydroxide, the residue was introduced into the vacuum-tube and the discharge passed until all trace of carbon dioxide was removed. The spectram of the remaining gas was compared with that of krypton, but no agreement was found in any of the lines.

The amount of helium given off by the mineral was in round numbers 100 e.cs. Had there been present with it $\frac{1}{10}$ of a c.c. of krypton, the spectrum of the latter would have been conspicuous when the residue was examined: hence the experiment points to the conclusion that krypton, if present at all, which is indeed doubtful, must amount to less than one part in a million of the helium content. As opportunity affords it is intended to carry on the investigation with respect to other strongly radioactive minerals, as it is not to be expected that definite results can be drawn from the behaviour of one mineral.

In conclusion I beg to express my thanks to Professor Strutt for suggesting this research and for his valuable advice during its procedure.

LXVIII. Radioactive Minerals in Common Rocks. By J. W. Waters, B.Sc., Imperial College of Science, South Kensington *.

T $\mathrm{T}$ has been shown by Rutherford and Strutt that a know1 ledge of the amount of uranium and also the amount of helium contained in a rock or mineral enables us to form a minimum estimate of its age. In making accurate measurements of these quantities it is much more convenient to experiment upon substances comparatively rich in radioactive constituents. Prof. Strutt has found that the phosphatic nodules and phosphatized bones which occur in

* Communicated by the Hon. R. J. Strutt, F.R.S. 
sedimentary rocks afford suitable material for the purpose. The object of the following investigation was to find in what minerals the radio-activity of igneous rocks is most concentrated, and, if possible, to separate them with a view to their use as material for finding the age of the rocks in which they occur.

The first material that was treated was rotted Cornwall granite from which kaolin and mica had been removed at a China-Clay Works. This was passed through a fine sieve and then washed with a gold-miner's pan to reject the lighter constituents, such as quartz and felspar. When the bulk was sufficiently reduced the lighter minerals which remained were removed by means of a heavy liquid (bromoform, spec. grav. $=2 \cdot 9$ ), those minerals whose specific gravity exceeds $2 \cdot 9$ sinking in the bromoform while the lighter ones float on the surface.

The heavy and light constituents were tested for radioactivity by finding their effect on the rate of leak of a goldleaf electroscope when spread over a tray placed inside the electroscope.

$\begin{aligned} \text { Normal rate of leak } & =4.0 \text { scale divs. per hour. } \\ \text { Increase due to heavy minerals } & =2.5 \quad, \\ , " & =0,\end{aligned}$

It thus appears that the radioactivity is concentrated in the heavier minerals; the lighter constituents were therefore rejected and further separation of the heavier minerals attempted. A little magnetite was removed with a permanent magnet and found to be non-radioactive. The residue was mainly tourmaline. This was removed by a comparatively powerful magnetic field produced by an electromagnet. The first part of this that was extracted was not active, but on removing the last traces of magnetic matter by a very powerful field a powder was obtained in which the Iadioactivity appeared to be concentrated. By concentrating the feebly magnetic mineral by magnetic fractionation a powder was obtained for which the corrected rate of leak was 16 scale divs, per hour. Un examination under the microscope this was seen to be distinguished by the presence of a number of small opaque fragments in some of which an hexagonal shape could be detected. The other minerals present, being of density not much greater than $2 \cdot 9$, were washed away by agitating the powder in bromoform. Advantage was also taken of the small size of the particles to obtain the active mineral pure by sifting.

About $\frac{1}{2}$ gram of the mineral was obtained from 2 or $3 \mathrm{lb}$. 
of the original material. The leak due to the final product was 2.5 scale divs. per minute or nearly 40 times the normal leak of the electroscope. Spectroscopic examination of the mineral showed that.titanium was present in large quantity. 'The mineral was therefore considered to be anatase or rutile.

Some of the mineral was tested for helium, and was found to contain about $1 \cdot 5 \mathrm{c} . \mathrm{mm}$. per gram.

The same methods were applied to a gneiss from the Inner Hebrides and the radioactivity was found to be concentrated in a very heavy, non-magnetic mineral, occurring in very small crystals. Examination under the microscope showed this to be zircon; this was contirmed by spectroscopic examination which showed zirconium to be present. A bout $\frac{1}{10}$ gram of the mineral was obtained from $1 \mathrm{lb}$. of the rock.

These experiments are being continued on other rocks.

I desire to thank Prof. Strutt for suggesting these experiments and for his interest and advice throughout.

\section{Proceedings of Learned Societies.}

\section{GEOLOGICAL SOCIETY.}

[Continued from p. 440.]
March 10th, 1909.-Prof. W. J. Sollas, IL.D., Sc.D., F.R.S., President, in the Chair.

HE following communications were read:-

1. "Some Notes on the Neighbourhood of the Victoria Falls (Khodesia).' By Thomas Codrington, M.Inst.C.E., F.G.S.

The author gives an account of the way in which the basalt lies in the valley of the Zambesi below and above the Victoria Falls, and points out how that has determined the features of the river. The basalt through which the Batoka Gorge has been cut appears in the course of the Zambesi for 2 miles above the Victoria Falls, causing rapids over rocky bars between many islands. It then disappears, and the river above flows quietly between alluvial flats for 5 miles, the basalt being traceable here and there below the water until above Candahar Island it again rises and constitutes the bed of the river from bank to bank, causing rapids that extend for many miles up the river. Attention is called to a wide tributary valley which joins the main Zambesi Valley on the east at the Falls; and to the Maramba River Howing down it, and its fluviatile deposits. The discovery of stone-implements and artificially-worked stones in the gravel and the bed of the Maramba is noted. 